\title{
What's the next step in evaluating laparoscopic pancreaticoduodenectomy?
}

\author{
Fernando Burdío, Luís Grande, Ignasi Poves \\ Department of Surgery, Hospital Universitari del Mar, Autonomous University of Barcelona. Barcelona, Spain \\ Correspondence to: Ignasi Poves. Department of Surgery, Hospital Universitari del Mar, Autonomous University of Barcelona, Barcelona, Spain. \\ Email: ipoves@parcdesalutmar.cat. \\ Comment on: Nickel F, Haney CM, Kowalewski KF, et al. Laparoscopic Versus Open Pancreaticoduodenectomy: A Systematic Review and Meta- \\ analysis of Randomized Controlled Trials. Ann Surg. 2019. [Epub ahead of print].
}

Submitted Jun 26, 2019. Accepted for publication Jul 12, 2019.

doi: $10.21037 /$ hbsn.2019.07.13

View this article at: http://dx.doi.org/10.21037/hbsn.2019.07.13

In the open approach, pancreaticoduodenectomy (PD) continues to be a high-risk procedure with a high rate of severe complications and a global death-rate of $9.2 \%$ and $10.1 \%$ in some developed European countries, such as France and Germany, respectively $(1,2)$. Most of reported volume-based outcome studies have found a strong inverse association between mortality and hospital volume. In a nationwide German hospital discharge data (2), riskadjusted mortality of very-low-volume $v s$. very-high-volume hospitals was $11.5 \%$ vs. $6.5 \%$, respectively.

Laparoscopic PD (LPD) started to be considered a possible technique after excellent results in selected cases were reported by Palanivelu et al. for first time in 2007: 42 LPD cases and a 2.3\% mortality rate (3). These results were reproduced by Kendrick et al. in 2010: 65 LPD cases and a $1.5 \%$ mortality rate (4). However, other centres failed to obtain any benefits or advantages from the laparoscopic approach and made a call for caution in its use (5). In the past years, large meta-analysis and casematch studies found similar results between OPD and LPD, but all these studies had been carried out using retrospective series. The first randomized controlled trial (RCT) was reported in 2017, again by Palanivelu et al., with good results favouring LPD in connection with reduced length of stay (PLOT trial). This study was monocentric and was carried out on selected cases: mean age was 58 years (patients $>70$ years were excluded), $92.2 \%$ of patients were ASA I-II, and only periampullary tumors were included (a slim $9 \%$ of cases were pancreatic carcinoma). Only one patient $(3.1 \%)$ required conversion to open surgery which confirms the experience of the surgical team and adequate patient selection. Later on, a second monocentric RCT was reported in 2018 (PADULAP trial), followed by a third multicentric study in 2019 (LEOPARD-2). In these last two RCTs, patient selection and technique-associated difficulties were similar: mean age 69 vs. 67 years; $46 \%$ vs. $30 \%$ ASA III; and conversion rate $23.5 \%$ vs. $20 \%$. Histologic pancreatic head cancer represented $59 \%$ vs. $29 \%$ in operated patients for PADULAP and LEOPARD-2 trials, respectively. While in the PADULAP trial, all LPDs were carried out by only one surgeon to avoid bias from the learning curve, the LEOPARD-2 trial was carried out in four different participating centres by 9 different surgeons who performed 50 LPDs. At interim analysis, LEOPARD-2 was closed in advance because of the high rate of severe intraoperative complications detected and $10 \%$ mortality in LPD. A systematic review and meta-analysis of these three RCTs has recently concluded that LPD shows no advantages over open PD, and recommends further studies focusing on patient safety during LPD (6). Although these conclusions are not very optimistic, it appears that it is only a matter of time that minimally invasive (laparoscopic and/ or robotic) PD will be accepted as an adequate procedure in selected cases and selected surgeons, as has been the case in other complex procedures in the history of surgery. It is very difficult to reach real conclusions from a meta-analysis of three RCTs carried out under different conditions and methods. Probably, new ongoing RCTs could help to yield some light on the real position of LPD.

Extensive previous experience in laparoscopic surgery 
is advisable before starting a LPD program. Acquisition of optimal laparoscopic skills varies among surgeons. Previous experience in other laparoscopic advanced techniques shortens the learning curve. The learning curve differs between studies, ranging from 20 to 40 cases. An analysis of the first 50 LPDs performed by 3 different surgeons showed that more than 30 cases are required until the LPD learning curve becomes stable (7). Probably, these figures will change in the future and will be contingent upon the experience of the leading surgeon of the pancreatic surgical team and ability of each centre to incorporate technical resources. The PADULAP trial demonstrated the positive influence of introducing new or more developed energy devices for improved safety and reduced operative time. Also, advances made in quality vision (Full HD, 3D) have clearly helped improve the surgeon's comfort and patient safety in both, resective and reconstructive phases. All these benefits and, especially those related to quality of postoperative patient comfort, are difficult to demonstrate in a trial. Mentoring and proctoring have been proposed as a safe method to overcome the learning curve. But even in this case, some surgeons from the LEOPARD-2 trial had worst results in the LPD group than during their previous participation in the learning curve, and recognized that more than 20 cases are needed. Young surgeons, residents and fellows have now gained dexterity on the use of laparoscopy principles since they first started their medical careers. In general, their ability in laparoscopic management should be better than that of actual surgeons. Although individual training in LPD has now become more readily available, there are not many referral centres with enough volume that offer live LPD procedures.

The results of the three reported RCTs clearly show that LPD can be safely performed by specially trained surgeons. However, open or laparoscopic PD are complex procedures and adequate patient selection can contribute to reduce the risk of intraoperative complications and conversion to open surgery. Nowadays, even major vascular resections can be performed by laparoscopy, which entails having superior surgical skills. Surgery of tumors in contact with large vessels should not be attempted until the learning curve is passed.

Cite this article as: Burdío F, Grande L, Poves I. B What's the next step in evaluating laparoscopic pancreaticoduodenectomy? HepatoBiliary Surg Nutr 2019;8(5):555-556. doi: 10.21037/ hbsn.2019.07.13

\section{Acknowledgments}

None.

\section{Footnote}

Conflicts of Interest: The authors have no conflicts of interest to declare.

Ethical Statement: The authors are accountable for all aspects of the work in ensuring that questions related to the accuracy or integrity of any part of the work are appropriately investigated and resolved.

\section{References}

1. Farges O, Bendersky N, Truant S, et al. The Theory and Practice of Pancreatic Surgery in France. Ann Surg 2017;266:797-804.

2. Krautz C, Denz A, Weber GF, et al. Influence of Hospital Volume Effects and Minimum Caseload Requirements on Quality of Care in Pancreatic Surgery in Germany. Visc Med 2017;33:131-4.

3. Palanivelu C, Jani K, Senthilnathan P, et al. Laparoscopic pancreaticoduodenectomy: technique and outcomes. J Am Coll Surg 2007;205:222-30.

4. Kendrick ML, Cusati D. Total laparoscopic pancreaticoduodenectomy: feasibility and outcome in an early experience. Arch Surg 2010;145:19-23.

5. Adam MA, Choudhury K, Dinan MA, et al. Minimally Invasive Versus Open Pancreaticoduodenectomy for Cancer: Practice Patterns and Short-term Outcomes Among 7061 Patients. Ann Surg 2015;262:372-7.

6. Nickel F, Haney CM, Kowalewski KF, et al. Laparoscopic Versus Open Pancreaticoduodenectomy: A Systematic Review and Meta-analysis of Randomized Controlled Trials. Ann Surg 2019. [Epub ahead of print].

7. Nagakawa Y, Nakamura Y, Honda G, et al. Learning curve and surgical factors influencing the surgical outcomes during the initial experience with laparoscopic pancreaticoduodenectomy. J Hepatobiliary Pancreat Sci 2018;25:498-507. 